worst, this agenda descends into relativism - the idea that someone's beliefs have as much weight as the so-called facts - or even Lysenkoism, in which the requirements of the state or of powerful groups take precedence over the facts. At its best, however, it can help scientists recognize how public hostility can be mobilized and consolidated despite the weight of peer-reviewed scientific evidence. This may happen because a culture of disrespect for science helps to reinforce cherished beliefs, or because experience has left individuals feeling betrayed by science or its application.

A major concern, especially in Europe, is to try to prevent such a climate enveloping nanotechnology. Experiences with genetically modified crops have led some governments to move towards being reflexive. At the same time, non-governmental organizations and other citizens' groups, more concerned about an emerging technology's potential disadvantages to their own interests, have welcomed the opportunity to tackle them as far upstream as possible.

It is in this context that two reports of citizens' participation are published this month. One, Informed Public Perceptions of Nanotechnology and Trust in Government by Jane Macoubrie of the Woodrow Wilson International Center for Scholars in Washington, is a study in which 177 members of the US public were briefed on nanotechnology and given a chance to explore its opportunities and their concerns. It documents weak public trust in regulatory agencies as a result of previous experiences with asbestos, dioxins, Agent Orange and nuclear power - exactly the type of cultural resistance to which Jasanoff and others would point. It also highlights a need to breed trust through better product labelling and compulsory regulation, and indicates a desire for information about the technology.

Another report, published in Britain this week, takes a less

conventional approach. Sponsored by Greenpeace, The Guardian newspaper and centres connected to the universities of Cambridge and Newcastle, it represents the outcome of a UK citizens' jury, in which 20 members of the public met repeatedly to hear from a variety of witnesses (see www.nanojury.org). The jury was asked about nanotechnology's benefits for the poor and disadvantaged (weak jury concerns), whether the public should determine when nanoparticles can be used in particular technologies (weak support), and whether it needs to yield more "quality leisure time" to deserve public funds (stronger support). As in the US study, the jury supported labelling, mandatory safety testing and better access to information about which nanotechnologies are being publicly funded.

These two studies reinforce the impression that the public has strong concerns about regulation and a lack of information about nanotechnology, and that nanotechnology is welcomed for its potential benefits. The results of the citizens' jury suggest that nanotechnology is not

"The results of the
citizens' jury suggest
that nanotechnology
is not perceived as a
serious threat."

perceived as a serious threat to the values of anyone but die-hard anti-technologists. But this was a small study, and one that thejurors themselves said is provisional.

Supporters of full-blown reflexiveness should welcome a transparent citizens' jury that has probed society's assumptions about the need for a technology, and should also acknowledge these appeals for communication and regulation. Meanwhile, governments have received some direct public guidance on citizens' interests that must be protected if nanotechnology is to flourish.

\title{
Science after Katrina
}

\section{The hurricane disaster on the Gulf coast will change the federal government's research priorities.}

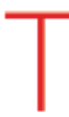
he clean-up operations in the wake of Katrina are a nightmare for all concerned, including scientists at Tulane University and other research institutions on the Gulf coast (see Nature 437, $177 ; 2005)$. They need all the help they can get, and other institutions must endeavour to provide it and get them back on their feet.

The ramifications of this tragedy will run deep. There are already signs that national priorities are changing: President George W. Bush, speaking in New Orleans on 16 September, broached some themes that he had previously avoided. "We have a duty to confront poverty with bold action," he said. If that pledge is to be followed through, it will involve changes in research priorities.

For better or for worse, the US federal government - particularly Congress - has a propensity to adjust the government's spending portfolio quickly in response to particular events. After the attacks of 11 September 2001, for example, the government created the Department of Homeland Security, with a large and ill-defined research programme, and diverted resources at the National Institutes of Health towards activities related to bioterrorism. Four years later, there is scant evidence that either shift has achieved much for science or for national security. After that precedent, some would argue that the government should avoid overreacting to Katrina.

Yet Katrina has brought to the surface some critical issues that have been wantonly ignored in Washington in recent years and now deserve some attention. The most significant of these relate to poverty, as Bush has now acknowledged, and racial division. Policymakers need good information if they are to tackle these issues, and in many instances research can provide it. The aftermath of Katrina will push poverty, at least, up the agendas of agencies such as the National Science Foundation and the National
"Policy-makers need good information if they are

to tackle poverty and racial division, and in many instances research can provide it."
Institutes of Health that support research in the social sciences and environmental health.

At the same time, the disaster raises the profile of two very different spheres of environmental research - water management and climate change. The former is quite well understood, although a great deal of existing knowledge about rivers and wetlands, for example, is frequently ignored by policy-makers. Despite the Bush administration's scepticism about the latter, it has maintained a powerful dimate-change science programme, which in time may shed valuable light on the complex relationship between global warming and extreme weather events, including hurricanes. 